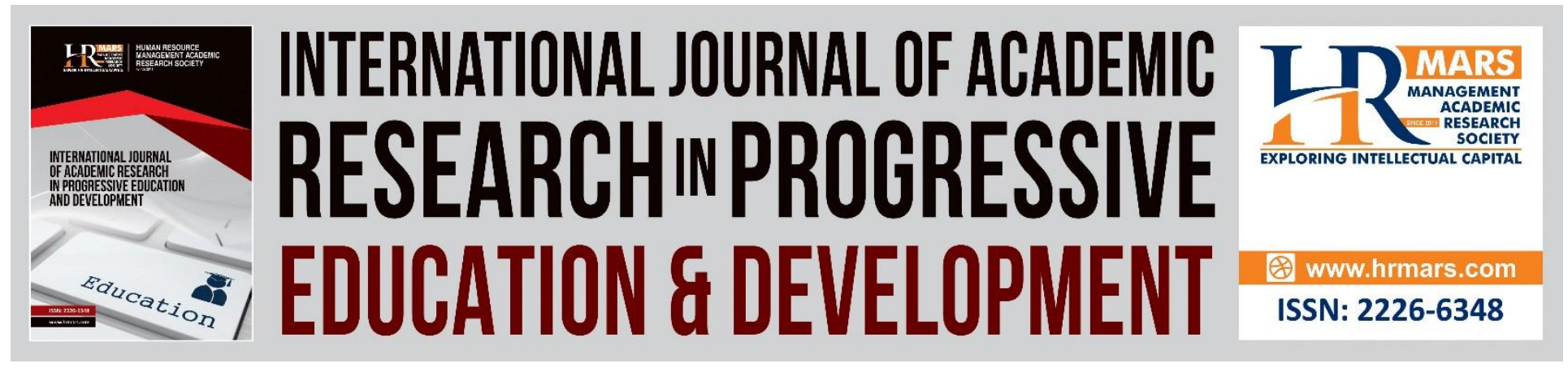

\title{
Physical Fitness Key Parameter for Sport Schools Young Athletes in Malaysia
}

Nur Hazshila Abd Hadi, Mohamad Razali Abdullah, Hafizan Juahir, Amir Ikram Rahim, Gunathevan Elumalai, Ahmad Bisyri Husin Musawi Maliki, Ahmad Nadzmi

To Link this Article: http://dx.doi.org/10.6007/IJARPED/v10-i2/8799 DOI:10.6007/IJARPED/v10-i2/8799

Received: 01 March 2021, Revised: 03 April 2021, Accepted: 27 April 2021

Published Online: 18 May 2021

In-Text Citation: (Hadi et al., 2021)

To Cite this Article: Hadi, N. H. A., Abdullah, M. R., Juahir, H., Rahim, A. I., Elumalai, G., Maliki, A. B. H. M., \& Nadzmi, A. (2021). Physical Fitness Key Parameter for Sport Schools Young Athletes in Malaysia.

International Journal of Academic Research in Progressive Education and Development, 10(2), 454-466.

Copyright: (C) 2021 The Author(s)

Published by Human Resource Management Academic Research Society (www.hrmars.com)

This article is published under the Creative Commons Attribution (CC BY 4.0) license. Anyone may reproduce, distribute, translate and create derivative works of this article (for both commercial and non-commercial purposes), subject to full attribution to the original publication and authors. The full terms of this license may be seen

at: $\underline{\text { http://creativecommons.org/licences/by/4.0/legalcode }}$

Vol. 10(2) 2021, Pg. 454 - 466

http://hrmars.com/index.php/pages/detail/IJARPED

JOURNAL HOMEPAGE

Full Terms \& Conditions of access and use can be found at

http://hrmars.com/index.php/pages/detail/publication-ethics 


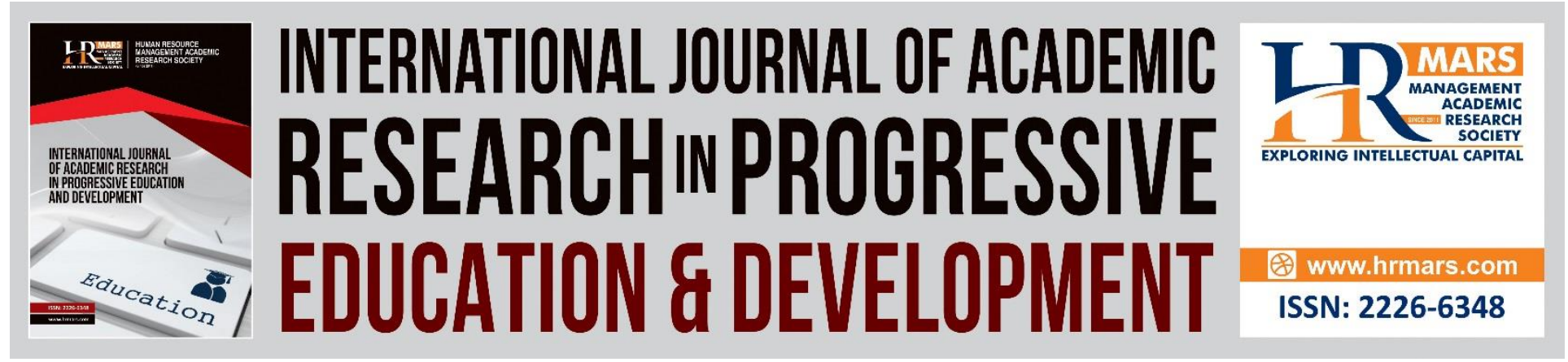

\title{
Physical Fitness Key Parameter for Sport Schools Young Athletes in Malaysia
}

\author{
Nur Hazshila Abd Hadi ${ }^{1}$, Mohamad Razali Abdullah², Hafizan \\ Juahir $^{2}$, Amir Ikram Rahim ${ }^{3}$, Gunathevan Elumalai ${ }^{3}$, Ahmad Bisyri \\ Husin Musawi Maliki ${ }^{2}$, Ahmad Nadzmi \\ ${ }^{1}$ Terengganu Malaysian sports school, ${ }^{2}$ East Coast Environmental Research Institute (ESERI), \\ University Sultan Zainal Abidin, ${ }^{3}$ Faculty of Sports Science and Coaching, Sultan Idris Education \\ University, Malaysia \\ Email: bisyrihusin84@gmail.com
}

\begin{abstract}
Physical fitness plays an important role in athlete for many purposes such as selection and talent identification. The purpose of this study is to identify the key parameter that contributed the most in young athlete in sport schools in Malaysia. A total of $n=5400$ athletes from 5 sport schools around Malaysia were participating in this study. 8 tests were used to measure physical fitness that is Standing Broad Jump, Standing Medicine Ball, Sprint 40-meter, 40m x 10 Shuttle run, Sit and Reach, Sit up, Push up, and Vertical jump. Descriptive statistic and Principal Component Analysis (PCA) were used to conduct a statistical analysis for this study. Result of the analysis found that there are several parameters were identified as the key parameters of physical fitness for sport school athletes in Malaysia. Conclusion, this study expanding the influence and relation between physical fitness motor componence and the athlete and further study is needed and recommended.
\end{abstract}

Keyword: Physical Fitness, Key Parameter, Sport Schools, Young Athlete, Malaysia

\section{Introduction}

Physical fitness has been of great significance for athletes in our lives from ages. Physical fitness includes physical ability of actively adapting to life, the ability of working and excising, and the ability of keeping resistance to disease, adapting to the environment of the survival. Physical activity (PA) and physical fitness are closely associated and mostly determined over weeks or months by PA trends. (Gu et al., 2016). Physical fitness is an essential predictor of health outcomes in children and adolescents and is designed as an integrated assessment of cardiorespiratory fitness, muscle fitness, flexibility and body composition (Ortega et al., 2008).

Although physical activity encourages motor development in youth, the long-term development of sport-specific sport ability will directly help young athletes benefit from 
endurance training and strength training (Baar, 2014; Gäbler et al., 2018). In addition to the development of sport-specific athletic skill during long-term development, a physical fitness evaluation may also be used to classify the talent. The skills and the potential of athlete can be established by these physical performance assessments and this can be used by coaches to hire or pick players, teams and colleges. It may also be used as a baseline for coaching and athletic references to improve athlete's success or to serve as a guideline for young students during the recruiting session.

Physical training plays a key and leading role in sports training. If a great athlete wants to achieve excellent results and climb to the top of world sports fitness, the first is to put a strong basis on physical fitness (Xu, 2015). In order to achieve this, athletes must continue to strengthen their physical training in order to adapt to the gradual increase in training load and intensity and to improve their competitive level.

Hill et al., (2020) from their study, there is discrimination in the selection of sports athletes. Players that are chosen initially for admission into the academy systems will also be more likely than excluded to obtain a career. One of the reasons for this study is the player's selection and success in academic soccer have been demonstrated to have two unchanging factors linked to age and biological maturation (Meylan et al., 2010). It is a challenge to recognize players with full potential for success at an adult level and it needs technological, tactical, physical, functional, psychological and cultural factors to be considered. It also says that a higher age of relativity is thought to have an advantage in success in accomplished sports (i.e. more time spent on skill-driven activities such as football). (Hill et al., 2020; Wattie et al., 2008). These recent studies will simplify the fact that sport is predicated specifically on athlete selection, and this is a key issue that can trigger a sports team' s probability or an individual's ability to become biased, and achievement in the sport is hardly attainable because of no particular criterion chosen for the sport or the team.

Baseline is a fixed point of reference that is used for comparison purposes. Baseline data are essential in recording performance of pre- and post-injury, monitoring recovery rates and assisting decision-making. (McKeever \& Schatz, 2003). Maliki et al (2020) stating that baseline data also can be used to evaluate athlete for talent identification in sport talent scout. For example, coaches can use the baseline to track athlete performance and can monitor the what intervention to use for the athlete. Absent of baseline data can cause lost tracking of athlete performance, lost guide for increasing athlete performance when the baseline data has been evaluated, hard to making decision and cannot be documented for any purpose.

Cattuzzo et al (2016) research aimed to review the scientific evidence on associations between motor competence (MC) and components of health-related physical fitness (HRPF), in children and adolescents. The studies conducted between 1990 and 2013 investigate the interactions of MC and HRPF components in healthy children and adolescents, such as body weight condition, cardiorespiratory fitness, musculoskeletal fitness and flexibility. The review has demonstrated good empirical evidence that reverberating $M C$ and body weight (27 of the 33 studies) with positive MC-cardiorespiratory fitness (12 out of 12 studies) and musculoskeletal fitness are positive (7 out of 11 studies).

Khodaverdi et al (2016) stating in their research that aimed to investigate whether perceived motor competence and components of health-related physical fitness mediated the 
relationship between actual motor competence and physical activity. The test of Gross Motor Development-2 and Marsh's Self-Description Questionnaire physical ability subscale were used to determine the actual motor capacity, perceived motor ability and physical activity of children. Body mass index, 600-yard running/walking, curling, push-up, and sit and reach physical exercise assessments measured. The result showed that the only fitness measure and perceived competence, aerobic fitness $(b=.28,95$ percent $\mathrm{Cl}=[.21, .339])$ was measures which mediated the relationship between the actual engine competency and fitness $(b=.16,95$ percent $\mathrm{Cl}=$ $[.12, .332])$.

Hypostasized that there are several physical fitness components contributing as a key parameter for physical fitness sport school's athlete in Malaysia. The purpose of this research is to identify the key parameter that contributed the most in young athlete in sport schools in Malaysia.

\section{Materials and Method \\ Research Design}

The research purpose is to identify the major factor of physical fitness on sport school student. To achieve the research purpose, quantitative data needed to collect for conducting the statistical data analysis. This research is a ex post facto that was designed to create a functional relationships among variables and to ensure the characteristic of human cannot be manipulated (Tuckman, 1972; Lord, 1973).

\section{Area of study}

This study examined Malaysia's Physical Fitness among sport school students results. This included 5 sport schools in Malaysia. Such schools include Sekolah Sukan Bukit Jalil (SSBJ), Sekolah Sukan Malaysia Pahang (SSMP), Sekolah Sukan Tunku Mahkota Ismail (SSTMI), Sekolah Sukan Malaysia Sabah (SSMS) and Sekolah Sukan Malaysia Terengganu (SSMT).

\section{Sample Size}

A total of $n=5400$ young elite athletes that selected from all 5 sport schools recruitment in Malaysia had participate in this study. This size sample is sufficient enough to be analysed by Principal Component Analysis (PCA) based on the previous study stating total adequacy sample size for PCA is scale: 50 - very poor; 100 - poor; 200 - fair; 300 - good; 500 - very good; 1000 or more - excellent (AL Comrey, 1992). Another study suggested that size sample range in their recommendations for precise result of PCA from an N of 50 to 400 (Barrett, 1981). With the total size sample of this study that is 5400 , with the reference from previous study, can be simplified that the total of size sample is more than enough and can resulting an excellent output in the data analysis then.

\section{Test Method}

Several physical fitness components were selected for this study. The selected physical component that involved in this study are leg power, upper body strength, speed, aerobic fitness, and flexibility, Procedures for participants fitness tests were conducted as follows. 
Vol. 10, No. 2, 2021, E-ISSN: 2226-6348 @ 2021 HRMARS

This form of consent is accorded to parents, guardians, school administrators and participants to address such problems such as study methodology, research objectives and others. Participants who plan to take part in data collection should undertake research. Participants' personal information and contact details, emergency contact information, health information and parent consent confirmation are some of the main components to be met by the parents under the consent form. This information is available only for research purposes. The investigator should not reveal all confidential details.

\section{Standing Board Jump (SBJ)}

This test has been used for leg strength analysis. Behind a slightly split leg line, participants will stand at the ground. A two-footer takeoff and landing were used while the arms were swinging back and knees rhythmically to about 90 degrees forward. (Azahari et al., 2019). Participants need to remember to jump to their feet without falling backwards. If you make a double jumping bug before your leap, you will terminate this test (SJB). The most detailed variables were considered and three trials were approved.

\section{Standing Medicine Ball Throw (SMBT)}

This test has been used to assess the strength of the top body. The standing medicine ball consisted of beginning with the width of the feet, the heels on the measuring line zero and keeping the medicine ball straight out at the foot (Stockbrugger \& Haennel, 2001). Participant were allowed to practice trials at least 5 to 6 times to obtain stable score and for familiarization with the technique required, including optimizing the angle of release and maximizing power output. After finishing the trial, participant was allowed to do the test for real scoring session. 3 measured trials in which they attempted to throw a medicine ball as far as possible. Each throw was measured for distance (meters).

\section{Sprint 40-meter (S40M)}

This test is used to measure speed and acceleration. The object of this test is to determine speed and acceleration. The test started with the front-foot toe directly behind the start line from the starting position. Participants had been instructed to go across the finish line with maximum effort from the beginning of the audio pass. (Chatzilazaridis et al., 2012). In order to avoid reaction time effects on results, no "go" signal was given.

\section{$40 m \times 10$ Shuttle run}

In this experiment, aerobic fitness was assessed. The test consisted of $6 \times 40 \mathrm{~m}$ sprints with 20 sprints of passive sprint recovery. The participants started 0,5m ahead sprinted $20 \mathrm{~m}$, hit a one hand cone and sprinted back as quickly as possible through the timing system. Best time in a single trial, mean time and loss of results can be measured in different ways (Gatterer et al., 2014).

\section{Sit and Reach (SAR)}

This SAR test was used for versatility measurement. The participants must sit on the floor, both perfectly straight and their knees face the flat surface of the sitting and touching the area. 
Vol. 10, No. 2, 2021, E-ISSN: $2226-6348$ @ 2021 HRMARS

(Rozi et al., 2019). The knee sides of the participant shall be held directly against the floor by the conductor with the least force. The participants slowly move their fingertips forward as the measurement slide passes as far as possible through the measuring line with hands-on top each other's with palms face down. The distance must be recorded by the conductor for a minimum of two seconds (Taha et al., 2018). The conductor must make sure participants are not making any jerky movements and the fingertips and legs are in a fixed straight position (Maliki et al., 2020). Test results shall be taken in multiples of $0.5 \mathrm{~cm}$.

\section{Sit up}

Used to assess the strength of the upper body. Sit-up test with knees bent on the ground at 90 degrees and feet flat and push-up testing with extended legs were performed (Abdullah et al., 2016). The number of completed sit-ups and push-ups in 1-minute was recorded.

\section{Push up}

The test was used for measuring the strength of the upper body. The participants took a prone position on the floor with their hands directly below their shoulders, extended legs and tucked toes so that they would be able to come into contact with the floor (push up position). The participants then push their arms to full extent and then drop their bodies down to the floor until their chest is down. The head-to-toe line should be straight at this point (Abdullah et al., 2017). All of these actions were executed only by the arms and shoulders. The score was determined by the number of push-ups while maintaining correct form.

\section{Vertical Jump}

This test has been used for leg power measurement. The player has to begin with the two straight legs in a ready state. The range is measured far as the max. measuring line crosses the side. Vertical jump tests are conducted to determine the height of the jump. While calculating the height of the jump, the time is also taken when the jump is done (Bisyri et al., 2018.).

\section{Statistical Analysis \\ Descriptive Statistic}

Descriptive and inferential statistics were performed using XLSTAT. To organise the data, descriptive statistics (mean and standard deviation) and the Principal Component Analysis (PCA) with confidence level of $p \leq 0.05$.

\section{Principal Component Analysis (PCA)}

Principal component analysis (PCA) is widely used in the processing of data and in reducing dimensionality. PCA were used as dimension-reduction tool that can be advantageously in some situation such as a problem of multivariate analysis may begin with a large number of correlated variables (Bro \& Smilde, 2014). PCA attempts to reduce a wide number of variables to a small set, which still maintains much of the big set variables. The PCA technique helps scientists to generate and use a limited number of variables called the principal factors. An analysis and interpretation of a reduced set is often better and easier. In this study, PCA were used to determine the best variables that contribute key parameter of physical fitness. 
Vol. 10, No. 2, 2021, E-ISSN: 2226-6348 @ 2021 HRMARS

There are 8 dependent variables which are SBJ, SMBT, S40M, 40-meter $\times 10$ shuttle run, SAR, Sit up, Push up, and Vertical Jump. By using the PCA, researcher can have reduced which variables that are contribute to the major factor of physical fitness. The result of PCA will show which variables that will be key parameter to dependent variables by using principal factors

\section{Result and Findings}

Table 1 shows the result of descriptive statistics of this research. First table showing the descriptive for qualitative data, stating the categories and frequencies of the sport school included in this research. Viewing from the result, school that have the most participant is SSMP with frequency total 1835 participants (33.9\%) and the school that have the lowest participant is SSMS with total frequency of 414 participants (7.6\%).

\begin{tabular}{llll}
\hline Variable & Categories & Frequencies & $\%$ \\
\hline School & SSBJ & 1384 & 25.6296 \\
& SSMP & 1835 & 33.9815 \\
& SSMS & 414 & 7.6667 \\
& SSMT & 617 & 11.4259 \\
& SSTMI & 1150 & 21.2963 \\
\hline
\end{tabular}

*note: SSBJ (Sekolah Sukan Bukit Jalil), SSMP (Sekolah Sukan Malaysia Pahang), SSMS (Sekolah Sukan Malaysia Pahang), SSMT (Sekolah Sukan Malaysia Terengganu), SSTMI (Sekolah Sukan Tengku Mahkota Ismail)

Table 1: Result of descriptive statistic for qualitative data

Table 2 shows the descriptive statistic result for quantitative data for this research, it is stating that SBJ have the highest mean (177.0741) with standard deviation (73.1930) and lowest mean goes to SMB with mean (5.1756) and with standard deviation (3.6558).

\begin{tabular}{llll}
\hline Variable & Observation & Mean & Std. deviation \\
\hline Standing Broad Jump (cm) & 5400 & 177.0741 & 73.1930 \\
Standing Medicine Ball Throw $(\mathrm{m})$ & 5400 & 5.1756 & 3.6558 \\
Speed 40 meter (sec) & 5400 & 5.8255 & 77.9868 \\
40m x 10 Shuttle Runs (minute) & 5400 & 6.6666 & 5.4727 \\
Sit and Reach (cm) & 5400 & 30.1508 & 16.4516 \\
Sit up & 5400 & 16.2635 & 22.9501 \\
Push up & 5400 & 13.2766 & 19.6047 \\
Vertical jump (cm) & 5400 & 8.7012 & 17.3918 \\
\hline
\end{tabular}

*note: Standing Broad Jump (SBJ), Standing Medicine Ball Throw (SMBT), Speed 40 meter (S40M), Sit and Reach (SAR)

Table 2: Result of descriptive statistic for quantitative data

\section{Identifying the key parameter of physical fitness test}

To achieve the main purpose of this research, PCA test was conducted. PCA test was conducted 2 times, before Varimax Rotation and after Varimax Rotation. the first is to identify the eigenvalue with an own value larger than one $(>1)$. The second was used for PCA with 4 
factor varimax rotation, which was used to define parameters with a loading factor greater than or equal to the parameter 0.5 factor loading that was defined from the first PCA.

According to the scree plot graph in figure 1 for the first PCA before the Varimax rotation in table 3 , is stated that there are three key parameters figured which has eigenvalue greater than one $(>1)$ that is F1 with the eigenvalue is 2.0172 with cumulative variability value $25.2151 \%$, F2 eigenvalue is 1.6962 with cumulative value $49.8295 \%$, F3 eigenvalue is 1.4723 with cumulative value $68.2331 \%$. For varimax rotation, further research was performed by adding two additional latent variables to the necessary understanding.

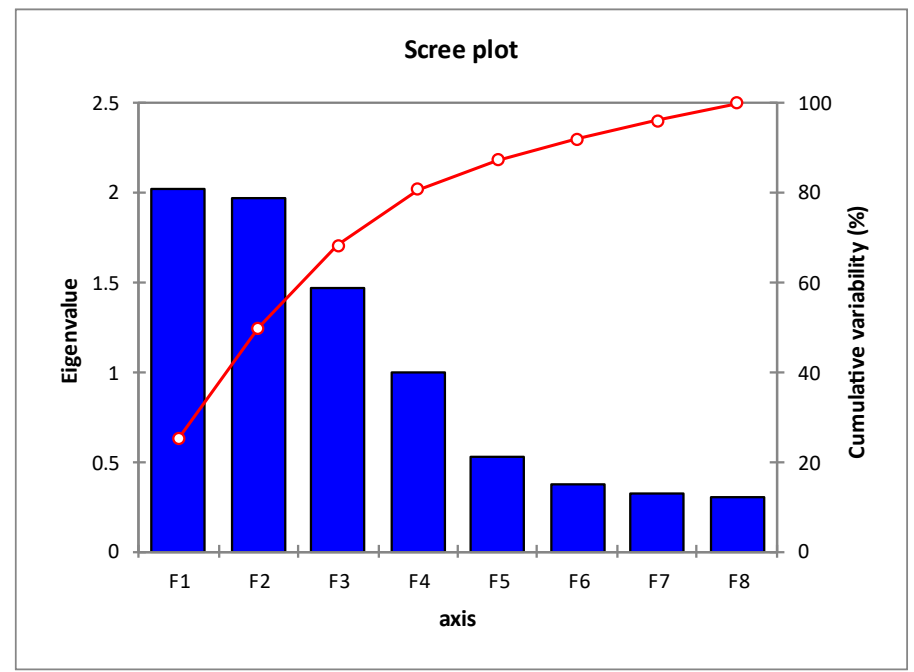

Figure 1: Scree plot graph of PCA

\begin{tabular}{lllllllll}
\hline & F1 & F2 & F3 & F4 & F5 & F6 & F7 & F8 \\
\hline & 2.017 & & & & & & & \\
Eigenvalue & 2 & 1.9692 & 1.4723 & 0.9948 & 0.5330 & 0.3765 & 0.3280 & 0.3090 \\
Variability & 25.21 & 24.614 & 18.403 & 12.435 & & & & \\
(\%) & 51 & 4 & 6 & 1 & 6.6624 & 4.7062 & 4.1002 & 3.8631 \\
Cumulativ & 25.21 & 49.829 & 68.233 & 80.668 & & 92.036 & 96.136 & 100.000 \\
e \% & 51 & 5 & 1 & 2 & 87.3305 & 8 & 9 & 0 \\
\hline
\end{tabular}

Table 3: Eigenvalue of PCA before Varimax Rotation

The PCA pattern is seen in Table 1 after the varimax rotation. With a combined variance of 68.23 percent, the result of the variance can be seen at 25.21 percent for D1, D2 (24.61 percent) and D3 (18.40\%). This result in table 4 stating that there are three key parameter that surpass the physical characteristics of the loading threshold factor (loading threshold factor > 0.7), which is Standing Broad Jump (SBJ) representing leg power motor performance, Standing Medicine Ball Throw (SMBT) representing upper body strength motor performance and Speed 40 Meter (S4OM) representing speed motor performance. The three-factor represents a powerful achievement in the physical fitness. 
Vol. 10, No. 2, 2021, E-ISSN: 2226-6348 @ 2021 HRMARS

\begin{tabular}{llll}
\hline & D1 & D2 & D3 \\
\hline Standing Broad Jump (cm) & 0.8539 & -0.0782 & 0.1348 \\
Standing Medicine Ball Throw $(\mathrm{m})$ & 0.4793 & -0.7652 & -0.0850 \\
Speed 40 meter (sec) & 0.0579 & -0.0455 & 0.1006 \\
40m x 10 Shuttle Run (minute) & 0.5764 & 0.4892 & -0.4776 \\
Sit and Reach (cm) & 0.8023 & 0.0308 & 0.0025 \\
Sit Up & 0.0510 & 0.4162 & 0.7934 \\
Push Up & 0.0323 & -0.0336 & 0.8993 \\
Vertical Jump (cm) & 0.1938 & 0.8647 & 0.1467 \\
\hline
\end{tabular}

Table 4: Factor loading after Varimax Rotation

\section{Discussion}

The primary focus of this research is to identify the key parameter that contributed the most in young athlete in sport schools in Malaysia. Overall, from the result, can simplified from the PCA result that there are three parameter that identified as key parameter. With the findings, the hypothesis of this research is proved and accepted. Stating that the parameter included as key parameter are SBJ (leg power), SMB (upper body strength) and S40M (speed and acceleration). Based on these results, it can be seen that it has similarities with previous studies from Cattuzzo et al (2016) with reported in their findings that found the motor competence (jump, throw, locomotor skill, and movement skill) and health related physical fitness (muscle strength and muscle endurance) play a great influence on athlete body and this finding have a similarities with this current research. Moreover, it also have similarities with another previous study from Khodaverdi et al., (2016) found that indicate the significant associations among all the measures were among locomotor skill, PA, aerobic fitness and perceived actual motor competence.

Leg power and speed component almost always been used in any sport especially team sport like football, basketball, baseball, and handball. These types of sport require many aspects of motor component and leg power plays an important role in order to execute an actual gameplay that required rapid movements, jumping and speed pace. Leg power and speed are important for readiness of the athlete to perform these different and rapid movements is essential and sprint performance may be considered relevant in these sports. Plyometric Training could potentially improve the athlete's ability to generate explosive ground reaction forces that contribute to the motor performance leg power and speed (Delecluse et al., 1995; Slimani et al., 2016).

Upper body strength also one of the important motor components in any type of sport like combat sport, team sport, individual sport, shooting sport and others. Upper body strength plays a strong influence on leg muscle strength by supporting leg muscles in determining speed and acceleration power and reducing the risk injury contact on leg muscle. There is study stating that there is a significant relation between the speed velocity and upper body strength (Speranza et al., 2015; Thomas et al., 2018). Another study from Gabbett et al (2012) found that the risk of injury was greater in slower athletes and those with lighter body mass. This show that to evade high injury risk, athlete's speed and upper body strength must be ideal in order to achieve low risk injury. Upper body strength is important for speed because begins with powerful arm action. 
The torque of the hip on one side of the body must be counteracted by the torque of the shoulder girdle on the other. For example, when the left glute creates power to drive the left foot into the ground, this power can be increased by having a strong arm swing on the right side, and the knee drive is also important, and this action is helped by a powerful upward swing of the opposite arm. This upswing is the result of strong shoulder and chest muscles (Ojo \& Oladipo, 2019).

From this, it can be simplified a good health related physical fitness and motor performance physical fitness will influence athlete performance positively. Therefore, in situation of elite athlete versus elite athlete, only skill will differentiate how the team or individual will achieve victory in competition. With this study findings, coaches can focus on boosting the athlete motor component more specific general training before follow up with specific sport trainings.

\section{Conclusion}

In conclusion, this study expanding the influence and relation between physical fitness motor componence and the athlete performance. Overall, this study stating the key parameter for physical fitness (motor component) for the sport schools' athlete are leg power, upper body strength and speed. With these findings, can be suggest that coaches should conduct the general athlete selection and new recruitment base on the key parameter founded in this study in order to avoid discrimination. Beside that, coaches can use these findings to create a new baseline for the recruitment and selection. Creating baseline can help coaches creating a benchmark for general recruitment and new recruitment of athlete in the future. Further study is recommended by based on parameter to discriminate which school have the excellent young athlete.

\section{Reference}

Abdullah, M. R., Bisyri, A., Maliki, H. M., Musa, R. M., Kosni, N. A., Juahir, H., \& Haque, M. (2016). Multi-Hierarchical Pattern Recognition of Athlete's Relative Performance as A Criterion for Predicting Potential Athletes. Journal of Young Pharmacists, 8(4), 463-470. https://doi.org/10.5530/jyp.2016.4.24

Abdullah, M. R., Nidzam, M. S., Hairi, A., Musa, R. M., Bisyri, A., Maliki, H. M., \& Kosni, N. A. (2017). Prediction of specific physical charateristic and fitness related variables on cardiovascular endurance among some selected male uniform arm units of University Sultan Zainal Abidin, Malaysia. In Health \& Exercise (Vol. 6, Issue 1).

AL Comrey, H. L. (1992). A First Course in Factor Analysis, 2nd Edn. Hiilsdale, NJ:L.

Azahari, H., Abdullah, M. R., Maliki, H. M. A. B., Eswaramoorthi, V., Juahir, H., Musa, R. M., \& Zawi, K. (2019). Physical fitness and anthropometric characteristics in school children: A comparison of urban and rural areas in east coast of Peninsular Malaysia. Indian Journal of Public Health Research and Development, 10(3), 619-623. https://doi.org/10.5958/09765506.2019.00570.9

Baar, K. (2014). Using Molecular Biology to Maximize Concurrent Training. Sports Med, 44(2). https://doi.org/10.1007/s40279-014-0252-0

Barrett, P. T. K. P. (1981). The observation to variable ratio in factor analysis. American Psychological Association PsycNet, 1(1). https://psycnet.apa.org/record/1982-20212-001

Bisyri, A., Maliki, H. M., Abdullah, M. R., Juahir, H., Abdullah, F., Ain, N., Abdullah, S., Musa, R. M., 
Vol. 10, No. 2, 2021, E-ISSN: $2226-6348$ @ 2021 HRMARS

Musliha Mat-Rasid, S., Adnan, A., Azura Kosni, N., Amalina, W. S., Muhamad, W., Afiqah, N., \& Nasir, M. (n.d.). A multilateral modelling of Youth Soccer Performance Index (YSPI) Related content The role of anthropometric, growth and maturity index (AGaMI) influencing youth soccer relative performance A multilateral modelling of Youth Soccer Performance Index (YSPI). https://doi.org/10.1088/1757-899X/342/1/012057

Bro, R., \& Smilde, A. K. (2014). Principal component analysis. In Analytical Methods (Vol. 6, Issue 9, pp. 2812-2831). Royal Society of Chemistry. https://doi.org/10.1039/c3ay41907j

Cattuzzo, M. T., dos Santos Henrique, R., Ré, A. H. N., de Oliveira, I. S., Melo, B. M., de Sousa Moura, M., de Araújo, R. C., \& Stodden, D. (2016). Motor competence and health related physical fitness in youth: A systematic review. In Journal of Science and Medicine in Sport (Vol. 19, Issue 2, pp. 123-129). Elsevier Ltd. https://doi.org/10.1016/j.jsams.2014.12.004

Chatzilazaridis, I., Panoutsakopoulos, V., \& Papaiakovou, G. (2012). Stride characteristics progress in a 40-m sprinting test executed by male preadolescent, adolescent and adult athletes. Journal Biology of Exercise, 8(2), 58-77. https://doi.org/10.4127/jbe.2012.0060

Delecluse, C., Coppenolle, H. V., Willems, E., Leemputte, M. V., Diels, R., \& Goris, M. (1995). Influence of high-resistance and high-velocity training on sprint performance. Medicine and Science in Sports and Exercise, 27(8), 1203-1209. https://doi.org/10.1249/00005768199508000-00015

Gabbett, T. J., Ullah, S., \& Finch, C. F. (2012). Identifying risk factors for contact injury in professional rugby league players - Application of a frailty model for recurrent injury. Journal of Science and Medicine in Sport, 15(6), 496-504.

https://doi.org/10.1016/j.jsams.2012.03.017

Gäbler, M., Prieske, O., Hortobágyi, T., \& Granacher, U. (2018). The effects of concurrent strength and endurance training on physical fitness and athletic performance in youth: A systematic review and meta-analysis. In Frontiers in Physiology (Vol. 9, Issue AUG). Frontiers Media S.A. https://doi.org/10.3389/fphys.2018.01057

Gatterer, H., Philippe, M., Menz, V., Mosbach, F., Faulhaber, M., \& Burtscher, M. (2014). Shuttlerun sprint training in hypoxia for youth elite soccer players: A pilot study. Journal of Sports Science and Medicine, 13(4), 731-735. http://www.jssm.org

Gu, X., Chang, M., \& Solmon, M. A. (2016). Physical activity, physical fitness, and health-related quality of life in school-aged children. Journal of Teaching in Physical Education, 35(2), 117126. https://doi.org/10.1123/jtpe.2015-0110

Hill, M., Scott, S., Malina, R. M., McGee, D., \& Cumming, S. P. (2020). Relative age and maturation selection biases in academy football. Journal of Sports Sciences, 38(11-12), 1359-1367. https://doi.org/10.1080/02640414.2019.1649524

Khodaverdi, Z., Bahram, A., Stodden, D., \& Kazemnejad, A. (2016). The relationship between actual motor competence and physical activity in children: Mediating roles of perceived motor competence and Health-Related physical fitness. Journal of Sports Sciences, 34(16), 1523-1529. https://doi.org/10.1080/02640414.2015.1122202

Lord, H. G. (1973). EXPOST FACTO STUDIES AS A RESEARCH METHOD.

Maliki, A. B. H. M., Abdullah, M. R., Nadzmi, A., Zainoddin, M. A. R., Puspitasari, I. M., Jibril, N. F. A., Nawi, N. A., Mat-Rasid, S. M., Musa, R. M., Suhaili, Z., Kamarudin, N. A., \& Ali, S. K. S. (2020). KIDS MOTOR PERFORMANCES DATASETS. Data in Brief, 34, 106582. 
INTERNATIONAL JOURNAL OF ACADEMIC RESEARCH IN PROGRESSIVE EDUCATION AND

DEVELOPMENT

Vol. 10, No. 2, 2021, E-ISSN: 2226-6348 @ 2021 HRMARS

https://doi.org/10.1016/j.dib.2020.106582

McKeever, C. K., \& Schatz, P. (2003). Current issues in the identification, assessment, and management of concussions in sports-related injuries. Applied Neuropsychology, 10(1), 411. https://doi.org/10.1207/S15324826AN1001_2

Meylan, C., Cronin, J., Oliver, J., \& Hughes, M. (2010). Talent Identification in Soccer: The Role of Maturity Status on Physical, Physiological and Technical Characteristics. International Journal of Sports Science \& Coaching, 5(4), 571-592. https://doi.org/10.1260/17479541.5.4.571

Ojo, O. R., \& Oladipo, I. O. (2019). EFFECT OF BODY WEIGHT RESISTANCE TRAINING ON POWER AND STRENGTH ABILITY AMONG SOCCER PLAYERS OF WESLEY UNIVERSITY ONDO.

Ortega, F. B., Ruiz, J. R., Castillo, M. J., \& Sjöström, M. (2008). Physical fitness in childhood and adolescence: A powerful marker of health. In International Journal of Obesity (Vol. 32, Issue 1, pp. 1-11). Nature Publishing Group. https://doi.org/10.1038/sj.ijo.0803774

Rozi, A. F. M., Abdullah, M. R., Rasid, S. M. M., Juahir, H., Maliki, A. B. H. M., Hashim, M. R., Alnamat, A. S. F., \& Bidin, M. N. (2019). The development of malaysian body somatotype model using comprehensive multivariate techniques. International Journal of Recent Technology and Engineering, 8(2 Special Issue 7), 264-267.

https://doi.org/10.35940/ijrte.B1053.0782S719

Slimani, M., Chamari, K., Miarka, B., Del Vecchio, F. B., \& Chéour, F. (2016). Effects of Plyometric Training on Physical Fitness in Team Sport Athletes: A Systematic Review. In Journal of Human Kinetics (Vol. 53, Issue 1, pp. 231-247). Polish Academy of Science, Committee of Physical Culture. https://doi.org/10.1515/hukin-2016-0026

Speranza, M. J. A., Gabbett, T. J., Johnston, R. D., \& Sheppard, J. M. (2015). Muscular Strength and Power Correlates of Tackling Ability in Semiprofessional Rugby League Players. Journal of Strength and Conditioning Research, 29(8), 2071-2078.

https://doi.org/10.1519/JSC.0000000000000897

Stockbrugger, B. A., \& Haennel, R. G. (2001). Validity and Reliability of a Medicine Ball Explosive Power Test. Journal of Strength and Conditioning Research, 15(4), 431-438. https://doi.org/10.1519/1533-4287(2001)015<0431:VAROAM>2.0.CO;2

Taha, Z., Musa, R. M., Abdul Majeed, A. P. P., Abdullah, M. R., Zakaria, M. A., Alim, M. M., Jizat, J. A. M., \& Ibrahim, M. F. (2018). The identification of high potential archers based on relative psychological coping skills variables: A Support Vector Machine approach. IOP Conference Series: Materials Science and Engineering, 319(1). https://doi.org/10.1088/1757899X/319/1/012027

Thomas, E., Bianco, A., Raia, T., Messina, G., Tabacchi, G., Bellafiore, M., Paoli, A., \& Palma, A. (2018). Relationship between velocity and muscular endurance of the upper body. Human Movement Science, 60, 175-182. https://doi.org/10.1016/j.humov.2018.06.008

Wattie, N., Cobley, S., \& Baker, J. (2008). Towards a unified understanding of relative age effects. Journal of Sports Sciences, 26(13), 1403-1409. https://doi.org/10.1080/02640410802233034

Xu, B. (2015). How to Improve the Athletes' Physical Fitness. Proceedings of the 2nd International Conference on Civil, Materials and Environmental Sciences, 11(Cmes), 282-284. https://doi.org/10.2991/cmes-15.2015.78 
INTERNATIONAL JOURNAL OF ACADEMIC RESEARCH IN PROGRESSIVE EDUCATION AND DEVELOPMENT

Vol. 10, No. 2, 2021, E-ISSN: 2226-6348 @ 2021 HRMARS

\section{Responses to Reviewers' Comments}

Dear editor,

This is our response to the reviewer's comment. Our response is stated below:

\begin{tabular}{|c|c|c|}
\hline No. & Reviewer's comment & Author's responses \\
\hline 1 & $\begin{array}{l}\text { Conclusion should be consisted of major findings of this } \\
\text { study. Researchers need to conclude major findings first } \\
\text { and then make appropriate suggestions. Suggestions } \\
\text { should be relevant to the problem with the explanation } \\
\text { that how this recommendation is appropriate in this } \\
\text { particular context and what will be the benefits of this } \\
\text { recommendation if implemented as per your findings. } \\
\text { Overall study is acceptable with minor correction } \\
\text { mentioned above. However, authors need to put some } \\
\text { lines/sentences in order to revise the conclusion and } \\
\text { recommendations part }\end{array}$ & $\begin{array}{l}\text { We accept the comments and } \\
\text { correction has been done in } \\
\text { this revised manuscript } \\
\text { following the reviewer's } \\
\text { comment. }\end{array}$ \\
\hline
\end{tabular}

